\title{
Identifying and validating freshwater ecoregions in Jinan City, China
}

\author{
Songyan $\mathrm{Yu}^{\mathrm{a}}$, Zongxue $\mathrm{Xu}^{\mathrm{a}, \mathrm{b}, *}$, Xingcai Liu ${ }^{\mathrm{c}}$, Tongwen Dou ${ }^{\mathrm{d}}$, Chen $\mathrm{Xu}^{\mathrm{e}}$ \\ ${ }^{a}$ College of Water Sciences, Beijing Normal University, Beijing 100875, China \\ boint Center for Global Changes Studies, Beijing 100875, China \\ ${ }^{c}$ Key Laboratory of Water Cycle and Related Land Surface Processes, Institute of Geographic Sciences and Natural Resources Research, Chinese Academy of Sciences, \\ Beijing 100101, China \\ d Jinan Survey Bureau of Hydrology and Water Resources, Jinan 250013, China \\ e School of Civil Engineering and Environmental Sciences, University of Oklahoma, Norman, OK 73019, USA
}

\section{A R T I C L E I N F O}

\section{Article history:}

Received 1 May 2015

Received in revised form 3 July 2015

Accepted 4 July 2015

Available online 9 July 2015

This manuscript was handled by

Geoff Syme, Editor-in-Chief

\section{Keywords:}

Freshwater ecoregions

City

Water quality

Land uses

\begin{abstract}
S U M M A R Y
Freshwater ecoregion is currently widely used by biologists, conservators and resource managers. Most of ecoregion delineations are developed at the basin scale and are not fully adapted in a practical manner because operational water resources management is primarily conducted by political administrative departments. In this study, an ecoregion delineation framework was proposed to classify three-level ecoregions in Jinan City with geographic information systems and cluster analysis. The first level ecoregion was composed of three watersheds (a part of the Yellow River, Xiaoqing River and Tuhaimajia River) plus the urban area, which was primarily determined on the basis of the city administrative divisions and river watersheds. The classification of the second level ecoregion is primarily based on the spatial heterogeneity of land use. The third level ecoregion was delineated for each second level ecoregion by using the cluster analysis on water quality. At the same time, administrative boundaries were used to rectify the boundaries of each ecoregion in this study to facilitate the administration of each ecoregion. Furthermore, ecological health assessment (IBI) based on fish communities were employed to validate the freshwater ecoregion. The results demonstrated that $73.3 \%$ of ecoregions were in line with the distribution of fish IBI, indicating that the freshwater ecoregions are acceptable for future water resources management.
\end{abstract}

(ㄷ) 2015 Elsevier B.V. All rights reserved.

\section{Introduction}

Ecoregions are large geographical regions that include multiple ecosystems, often with similar functions (Bailey, 1983), and have been widely used in resources management since they were issued (Omernik, 1987). Ecoregion delineation initially focused on terrestrial ecosystems, and Omernik (1987) expanded it to aquatic ecosystems. Aquatic ecosystem delineations are based on the assumption that freshwater ecosystem processes are systematically influenced by environmental processes operating at the landscape scale (Maxwell et al., 1995; Soranno, 2010), Therefore, aquatic ecoregions is the unit that includes the homogenous freshwater ecosystems and related surrounding lands. The development of freshwater ecoregions has many potential uses for biologists, conservators and resource managers in conservation and management of water resources (Kennard et al., 2010), aquatic species

* Corresponding author at: College of Water Sciences, Beijing Normal University, Beijing 100875, China.

E-mail address: zongxuexu@vip.sina.com (Z. Xu).
(Abell et al., 2008), aquatic ecosystems and habitats (Munne and Prat, 2004), and also in water quality monitoring (Ravichandran et al., 1996) and river health assessment (Binckley et al., 2010).

Many aquatic ecoregion delineation systems have been developed in the world (Kennard et al., 2010), including North America (Omernik, 1987) and Australia (Davies et al., 2000). However, two distinct problems still exist for further applications in modern water resources management. First, many previous attempts to delineate ecoregions corresponded approximately to a drainage basin. In fact, the fundamental aquatic ecosystem management unit at least in China is the Water Department within a city, which means it is also necessary to perform aquatic ecoregion delineations within the city scope; on the other hand, previous ecoregion delineations may lead to management confusion. For aquatic ecosystem conservation, the reason for degradation may be from the surrounding environmental factors or the upper basin in another administrative unit. To identify the relationship between the power and the responsibility, aquatic ecoregion delineation needs to be performed, not only in a drainage basin but also within a city. 
The second problem, the subjective and intuitive ecoregions resulting from different selected indicators instead of repeatable selecting methods, has prevented ecoregion delineation from being derived from a framework of regulated indicators. Because the spatial pattern of any particular variable might correspond to certain eco-regional characteristics when it was applied to identify ecoregions, different ecoregions will vary in their degree of homogeneity, and the change at the boundaries between different ecoregions could fluctuate in a manner specific to the locality (Jenerette et al., 2002). To guarantee the relative stability of borders and even the formality of aquatic ecoregions, a repeatable indicator framework should be developed (Kong et al., 2013).

Terrestrial processes were recognized to have a significant influence on the state of water body (Peterjohn and Correll, 1984; Summer et al., 1990). Particular variables such as physiography, soil characteristics, and land uses were found to be important to affect water quality and even aquatic ecosystem health (Geleta et al., 1994; Jenerette et al., 2002; Shirmohammadi et al., 1997). Aquatic ecoregions could be identified according to the spatial patterns of the driving factors (Bailey et al., 1985; Bailey, 2005; Graef et al., 2005; Omernik and Griffith, 1991). Most studies focused on aquatic ecoregions within a whole watershed or country, rather than in a city. Considering the water resources management practice in China, Jinan City was selected as a case study to delineate three-level aquatic ecoregions which may moderate the conflict of interest between different authorities in watershed management.

Much of this work - including freshwater ecoregion delineation within a city and a repeatable indicator framework - has not been adequately conducted up to date. Thus, this paper aims to use statistical methods to develop an acceptable indicator framework based on the concept of aquatic ecoregions. Additionally, factors considered during ecoregion delineation in a watershed are quite different from those in a city. Administrative boundaries and rivers often overlap, effectively dividing watersheds (Jenerette et al., 2002), while traditional ecoregions used to include a complete basin for ecological reasons (Bailey, 2005). Additionally, for modern water resources management, freshwater ecoregions in a city are required for local river management. Therefore, we try to identify aquatic ecoregion boundaries according to local political boundaries other than the boundaries of watersheds.

The objective of this study is to use rigorous analysis procedures, especially modern statistical methods, to develop a repeatable indicator framework applied for identifying freshwater ecoregions in Jinan City. Then, the ecoregion results will be assessed for accuracy in describing the homogeneity within ecoregions and maximizing the heterogeneity among ecoregions. Finally, appropriate freshwater ecoregions will be illustrated for water resources management in Jinan City.

\section{Materials and methods}

\subsection{Study area description}

Jinan City is located in the warm-temperature and semi-humid continental monsoon district. This city's land consists of three major watersheds, which are the Yellow River watershed, the Xiaoqing River watershed and the Tuhaimajia River watershed, with total areas of $2778 \mathrm{~km}^{2}, 2792 \mathrm{~km}^{2}$ and $2400 \mathrm{~km}^{2}$, respectively. They have few hydrological connections with each other, and their headwaters come from different districts, so that we could expect there to be a few differences among the three aquatic ecosystems. The part of the Yellow River in Jinan City belongs to its downstream section, which merges into the Bohai Sea in the city of Dongying next to Jinan. The riverbed is quite broad (up to $200 \mathrm{~m}$ wide), and interestingly there are only a few branches merging into the Yellow River in Jinan because abundant sediment concentration causes the bottom of the riverbed to be higher than the surrounding ground. The Xiaoqing River, which crosses through the urban area, is important for the urban district, domestic life and industrial development in Jinan. The Tuhaimajia River, which is located in the alluvial plains of the north of Jinan, is regarded as the main water resource for irrigation, as it flows through densely populated areas with a large amount of farmland.

\subsection{Freshwater ecoregions delineation}

The identification of the freshwater ecoregions included four steps as follows.

\section{Step 1: Environmental data collection and processing}

To monitor the water quality of river ecosystems within Jinan City, we conducted three extensive field surveys (Fig. 1): May 1st-20th, August 2nd-21st and November 1st-20th, 2014. Nine representative parameters were selected for the freshwater ecoregion delineation, including electrical conductivity (Ec), dissolved oxygen (DO), total nitrogen (TN), ammonia nitrogen $\left(\mathrm{NH}_{3}-\mathrm{N}\right)$, nitrite nitrogen $\left(\mathrm{NO}_{2}-\mathrm{N}\right)$, nitrate nitrogen $\left(\mathrm{NO}_{3}-\mathrm{N}\right)$, permanganate index $\left(\mathrm{COD}_{\mathrm{Mn}}\right)$, biochemical oxygen demand (BOD), and total phosphate (TP). The values of Ec and DO were directly measured in-situ using a YSI-85 multiparameter water quality monitoring instrument. The others were collected at the monitoring sites and tested in the laboratory within $24 \mathrm{~h}$.

Fishes were also collected in the field surveys. Sites were fished for a maximum of $30 \mathrm{~min}$ and for no more than $100 \mathrm{~m}$, which represented different types of habitats (i.e., riffle, run, and pool). In wadeable streams, fish were collected by a two person fish collection team, i.e., one individual used the backpack electrofisher with two handheld electrodes and one was responsible for netting fish with dip nets (Wu et al., 2014). In unwadeable streams, seines (30 and $40 \mathrm{~mm}$ mesh size) were used for fishing by boat, and electrofishing equipment was used to ensure a good representation of the fish at the site. All fish individuals (with total length longer than $20 \mathrm{~mm}$ ) collected were identified to species. The ecological health assessment was conducted using the Index of Biological Integrity based on fish community (IBF, see Wu et al., 2014 for details).

A digital elevation model $(D E M)$ at a $30 \times 30 \mathrm{~m}$ resolution was used to extract sub-basins by ArcGIS software. The delineated sub-basins were employed for identifying ecoregions using cluster analysis.

Landuse information was obtained from the Resource and Environmental Sciences Data Center of CAS (Chinese Academy of Science). Data were provided in a $30 \times 30 \mathrm{~m}$ resolution, and included information from six land use categories (Fig. 2): (1) agricultural land, including paddy field and dry land; (2) forestland, including shrub land and sparse woodlot; (3) grassland, including different coverage types; (4) construction land, including industrial and residential area; (5) water bodies, including rivers, wetlands and sandy beaches; and (6) barren land, including gravel, bare ground and bare rocks. Actually, only forestland and barren land were selected in this study for the following analysis due to their appropriate spatial heterogeneity, while the spatial homogeneity of other land use types were too high or too low to be applied for ecoregion delineation (Fig. 2).

\section{Step 2: Selection of freshwater ecoregion indicators}

Selection of indicators is vital in freshwater ecoregion delineations, which should be in accordance with the classification of 


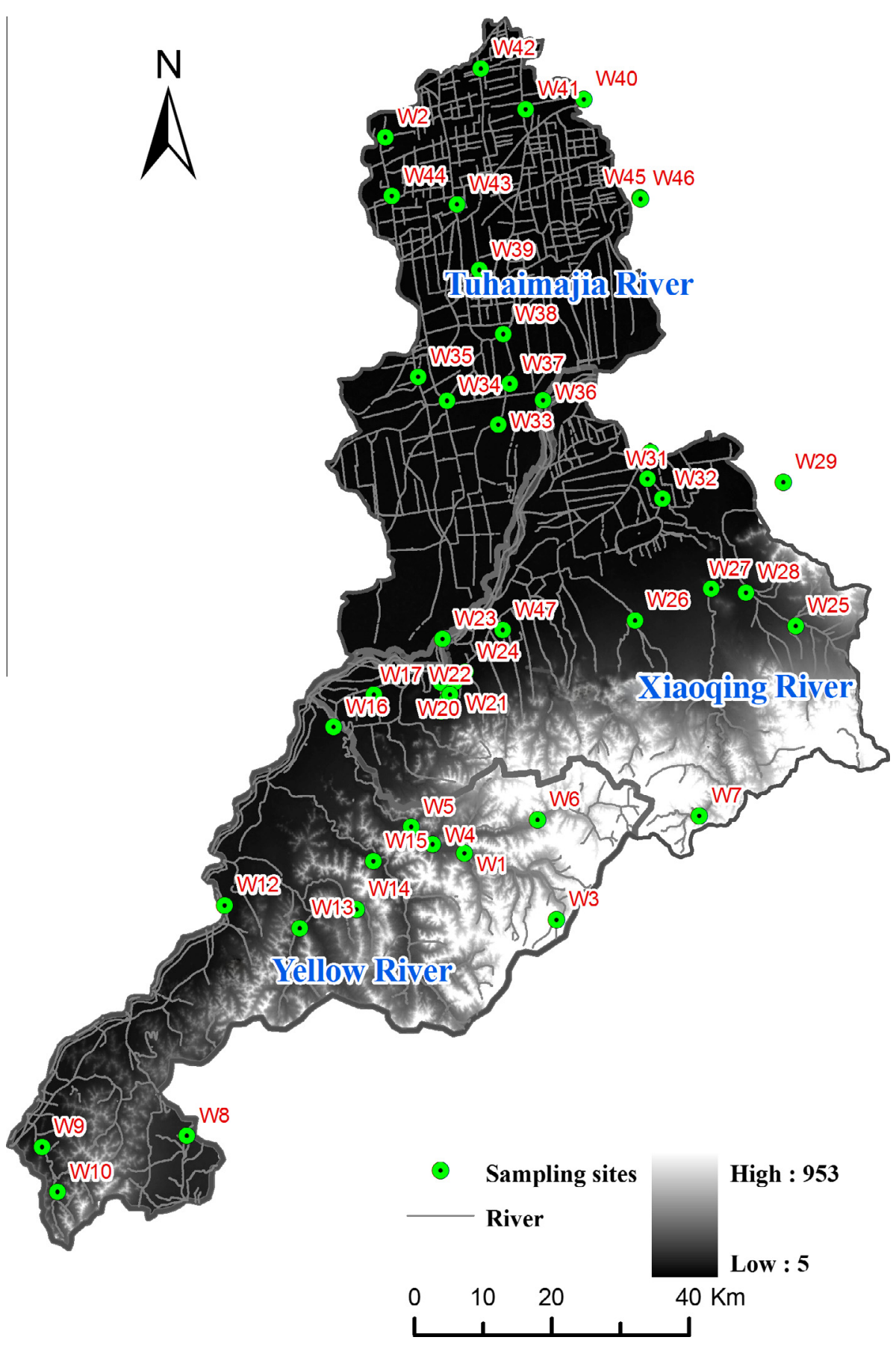

Fig. 1. Study area with aquatic ecosystem monitoring stations.

ecoregions. The aquatic ecoregion application (Omernik, 1987) or other broad-scale terrestrial delineations are based on climate and terrestrial vegetation (e.g., DMEER, 2000), as well as on runoff depth (Kong et al., 2013). Actually, these three factors were telling the same story, which all focused on water resources. However, the condition in this study is a little different from the previous. As mentioned, the area of Jinan City is approximately $8200 \mathrm{~km}^{2}$, where distributions of precipitation and vegetation are not heterogeneous enough to identify distinct freshwater ecoregion patterns. Though almost the same precipitation amount occurs throughout the city, the elevation factor has an effective influence on the distribution of water resources, affecting water converge from the high mountain to the alluvial plains and then to the estuary. Rugged ground creates different landscapes by determining water flow directions, and because water resource is the dominant factor in shaping aquatic ecosystems, we thus take the elevation into consideration as a freshwater ecoregion indicator.

In addition, surface runoff carries soil particles with various contaminants when crossing through different land use types in the flow convergence process. It has long been recognized that land use patterns or landscapes showed significant association with river or lake water quality (Allan et al., 1997; Hurley and Mazumder, 2013; Sliva and Williams, 2001), particularly at the riparian scale. In this study, correlation analysis between freshwater community and land use types (Table 1 ) showed that forestland and barren land were significantly related to fish, zooplankton and phytoplankton assemblage attributes and water quality parameters. Despite very different approaches, land use patterns have 


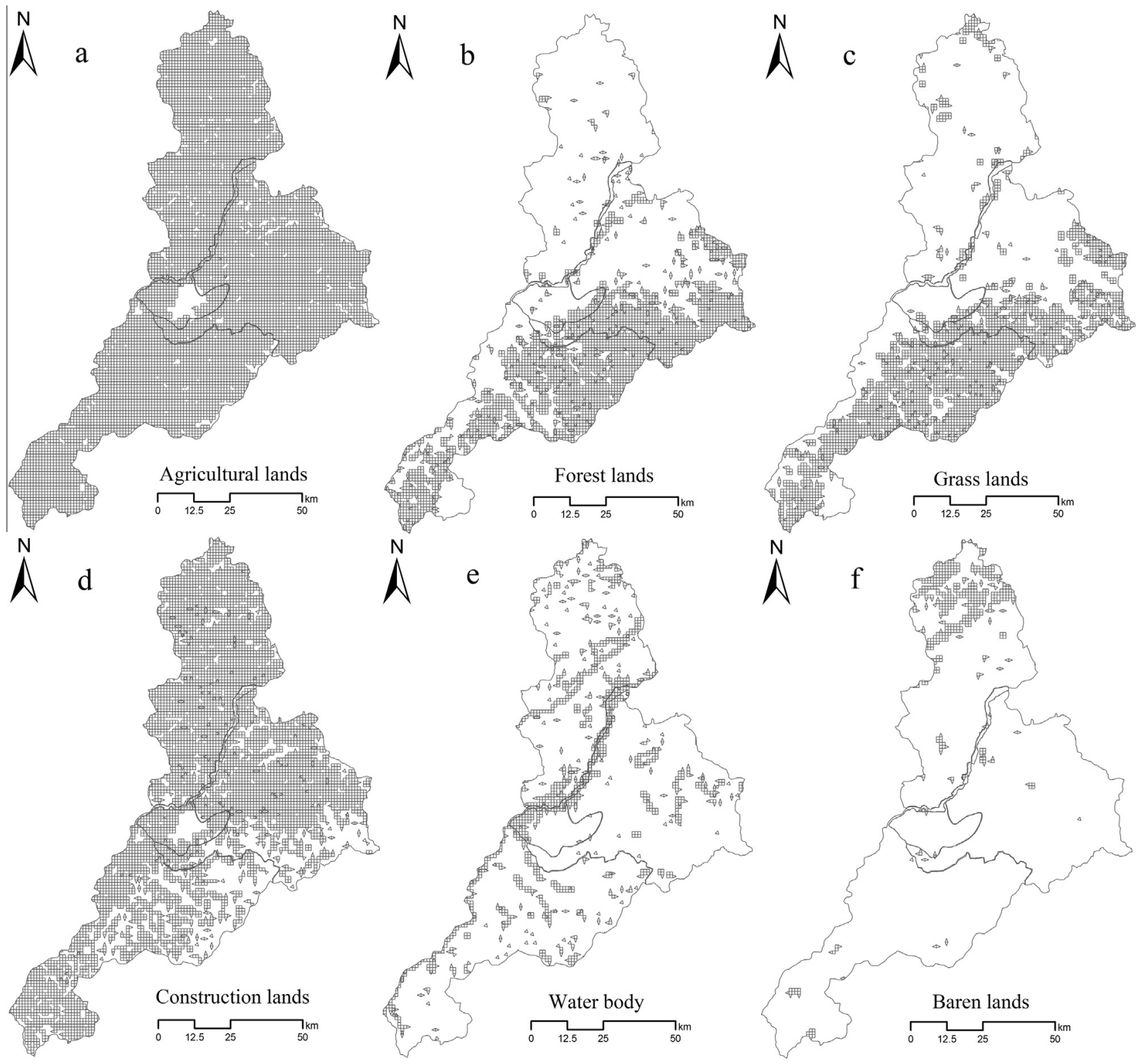

Fig. 2. Spatial patterns of the six land use types in Jinan City. A grey grid indicates that the landuse type covers at least $25 \%$ of the grid area.

been widely applied in various ecoregion frameworks (Bailey, 2005; Kong et al., 2013).

Soil type was also used for delineation in previous research on identifying ecoregions. However, because of the relatively small area of Jinan City, there are only three sorts of soil found (moisture soil, cinnamon soil and brown soil) (Wen, 2010), indicating insufficient heterogeneity to be applied in this study. Soil type is thus omitted from the following analysis.

Compared to terrestrial ecosystem components, riverine water quality affected aquatic ecosystems more directly. Physicochemical characteristics of water are not only important components of aquatic ecosystems, but are also the reflections of the environment for aquatic ecological organisms, by which the features and functions of a freshwater ecological community are shaped to some extent (Allan et al., 1997). Water quality is different from climate, land use and other terrestrial ecosystem components because it fluctuates at a smaller temporal and spatial scale, which means that it could be employed as a lower level ecoregion index. Therefore, collectively three indices (elevation, land use types and water quality) are appropriate for identifying aquatic ecoregions in Jinan City.

For the first level ecoregion, distributions of water resources and sources of river water are considered to be two important factors. The DEM map (Fig. 1) shows that Jinan City's political area tends to decrease in elevation from south to north, leading river water to flow from the southern mountain to the northern alluvial plains. Two facts should also be noted. First, the three rivers (the Yellow, Xiaoqing and Tuhaimajia Rivers) have no hydrological connection and come from distinct headwater sources. For instance, the Yellow River originates from the Tibet plain, while the Xiaoqing River is a local stream whose source is located in the southern hilly mountains. Aquatic ecosystems within these two different rivers are expected to be distinctly different. Second, the characteristics of the city administrative divisions are anticipated to be far from those of the natural landscape or countryside. The results from our three field surveys suggested that very intensive human activities caused the deterioration of the environment to the extent that all 18 representative fish species were absent at 
Table 1

Correlation between freshwater community features and land use types.

\begin{tabular}{|c|c|c|c|}
\hline & Community features & $\begin{array}{l}\text { Forest } \\
\text { land }\end{array}$ & $\begin{array}{l}\text { Barren } \\
\text { land }\end{array}$ \\
\hline \multirow[t]{3}{*}{ Fish assemblages } & Density & 0.231 & $-0.554^{*}$ \\
\hline & $\begin{array}{l}\text { Shannon-Weaver } \\
\text { Index }\end{array}$ & 0.036 & -0.094 \\
\hline & Evenness & 0.140 & $0.567^{*}$ \\
\hline \multirow[t]{3}{*}{ Zooplankton assemblages } & Density & $-0.589^{*}$ & -0.047 \\
\hline & $\begin{array}{l}\text { Shannon-Weaver } \\
\text { Index }\end{array}$ & $-0.602^{*}$ & 0.220 \\
\hline & Evenness & 0.210 & 0.189 \\
\hline \multirow{3}{*}{$\begin{array}{l}\text { Phytoplankton } \\
\text { assemblages }\end{array}$} & Density & $-0.551^{*}$ & 0.216 \\
\hline & $\begin{array}{l}\text { Shannon-Weaver } \\
\text { Index }\end{array}$ & $-0.556^{*}$ & $0.540^{*}$ \\
\hline & Evenness & $0.541^{*}$ & -0.008 \\
\hline \multirow[t]{9}{*}{ Water quality } & Ec & $-0.605^{*}$ & -0.211 \\
\hline & DO & 0.299 & $0.530^{*}$ \\
\hline & TN & -0.012 & 0.132 \\
\hline & $\mathrm{NH}_{3}-\mathrm{N}$ & -0.118 & $-0.600^{*}$ \\
\hline & $\mathrm{NO}_{2}-\mathrm{N}$ & 0.136 & -0.124 \\
\hline & $\mathrm{NO}_{3}-\mathrm{N}$ & 0.092 & $0.571^{*}$ \\
\hline & $\mathrm{COD}_{\mathrm{Mn}}$ & $0.625^{*}$ & $-0.563^{*}$ \\
\hline & BOD & $0.546^{*}$ & -0.048 \\
\hline & $\mathrm{TP}$ & $-0.587^{*}$ & $-0.542^{*}$ \\
\hline
\end{tabular}

* Denotes significant relationship at a level of $p<0.05$.

most sites (67\%) in the urban area (Zhao et al., 2015). Given that special status and the highly intensive anthropogenic activities, the urban area is supposed to be independent of the surrounding ecosystems.

For the second level ecoregion, middle-scale spatial variability of environmental attributes is suitable in this type of classification. Semi-variance analysis showed that elevation, annual precipitation, annual evapotranspiration, and land uses (forestland and barren land) were spatially autocorrelated, and the minor ranges were $53 \mathrm{~km}, 434 \mathrm{~km}, 448$ km, 16 km and 14 km, respectively. Jinan City is approximately $100 \mathrm{~km}$ long diagonally, suggesting that spatial variability of land use types such as forestland and barren land can be reflected in the second level delineation.

For the third level ecoregion (the lowest level in this study), the ecoregion indicators needed are ones that are at the smallest spatial and temporal scales, and water quality parameters satisfy this criteria. A total of 45 sampling sites were set in three field surveys, which covered each of the three river watersheds, meaning that a sufficient water quality dataset was developed for the following analysis.

\section{Step 3: Freshwater ecoregion delineation approach}

Because subsystems can be understood only within the context of the whole, the classification of freshwater ecoregion begins with the largest units and successively subdivides them (Bailey, 2005). The first level ecoregion is recognized by dissecting the whole Jinan City area into parts on the basis of differences in water resources, water sources and elevation. Similarly, the second level ecoregion would also be developed by subdividing the first level based on the spatial patterns of forestland and barren land. This approach is referred to as "from above".

To ensure the integrity of units and the significance of hydrological drainage area, the third level ecoregions were identified from the lower level units (Liu et al., 2010). On the basis of the second level ecoregions, divided sub-catchments were compared in terms of water quality patterns, and the adjacent sub-catchments with similar patterns were combined into one third-level ecoregion, and so forth. Finally, the approach to delineating third level ecoregions can be referred to as "from below".
Step 4: Adjustment of the initial ecoregions results

In practice, there are two water resource management systems in China. One is based on the large river basins, such as the Changjiang Water Resources Commission of the Ministry of Water Resources and the Yellow River Conservancy Commission of the Ministry of Water Resources, which are for water resource management of the Changjiang River and the Yellow River, respectively. The other is based on political boundaries, including the Water Resources Department or the Water Conservancy. The research of aquatic ecoregions in Jinan City belongs to the second administrative system. Therefore, the boundaries of each ecoregion in this study were rectified to fit the boundaries of political units, so there is a practical advantage in adjusting statistically determined ecoregion boundaries to follow administrative borders.

\section{Results analysis}

\subsection{Freshwater ecoregion delineation}

The boundaries of the three catchments were extracted based on DEM, which is the preliminary delineation of the first level ecoregion (Fig. 3). The urban area of Jinan City is mainly located in the Xiaoqing River Catchment. The field surveys showed that no fish were found in $50 \%$ of sampling sites in the urban area, but only $10 \%$ in the natural area. Furthermore, the attributes of the zooplankton community are also significantly different in the urban area than in the natural area (Table 2), especially for the attributes of species numbers and density $(p<0.05)$. Therefore, the urban area was identified as an independent ecoregion, so that four first-level ecoregions in total were identified in Jinan City, and the four freshwater ecoregions were then named the Yellow freshwater ecoregion, Xiaoqing freshwater ecoregion, Urban freshwater ecoregion and Tuhaimajia freshwater ecoregion.

For the second level freshwater ecoregion, barren land was mostly distributed in northern Jinan, while the forestland was in the south (Fig. 4). On the foundation of the higher level (the first level), the Yellow freshwater ecoregion (I) could be subdivided into three parts (I-1, I-2 and I-3), where I- 1 and I- 2 are separated by I-3, which was primarily covered by forestland; it is the same in the Xiaoqing freshwater ecoregion (III) and the Tuhaimajia freshwater ecoregion (IV), where III- 2 and IV- 1 were mostly characterized by forestland and barren land, respectively, but III- 1 and IV-2 were not. The Urban freshwater ecoregion (II) was still maintained as an independent and intact ecoregion.

To maintain the natural integrity of the drainage pattern, the city was classified into 153 sub-catchments (Fig. 5 left). Combined with the spatial cluster results of water quality (Fig. 5 middle), the freshwater ecoregion boundaries could be then established using the principle of maintaining the boundary integrity of sub-catchments in the first stage. As the third-level ecoregion was supposed to be set at the county scale, the lowest level of political authority in China, county boundaries were applied to rectify the first-stage ecoregion. For example, solely based on the water quality pattern in I-3, there was no third-level freshwater ecoregion existing; but by taking into account the boundaries between the Changqing County and Pingyin County, the Changqing County and the Lixia County, I-3 was then subdivided into three lower level ecoregions (Fig. 5 right).

\subsection{Freshwater ecoregion assessment}

The freshwater ecoregion is regarded as a reliable determination of a spatially eco-hydrologic heterogeneous nature, which could be used to effectively and efficiently manage water resources 

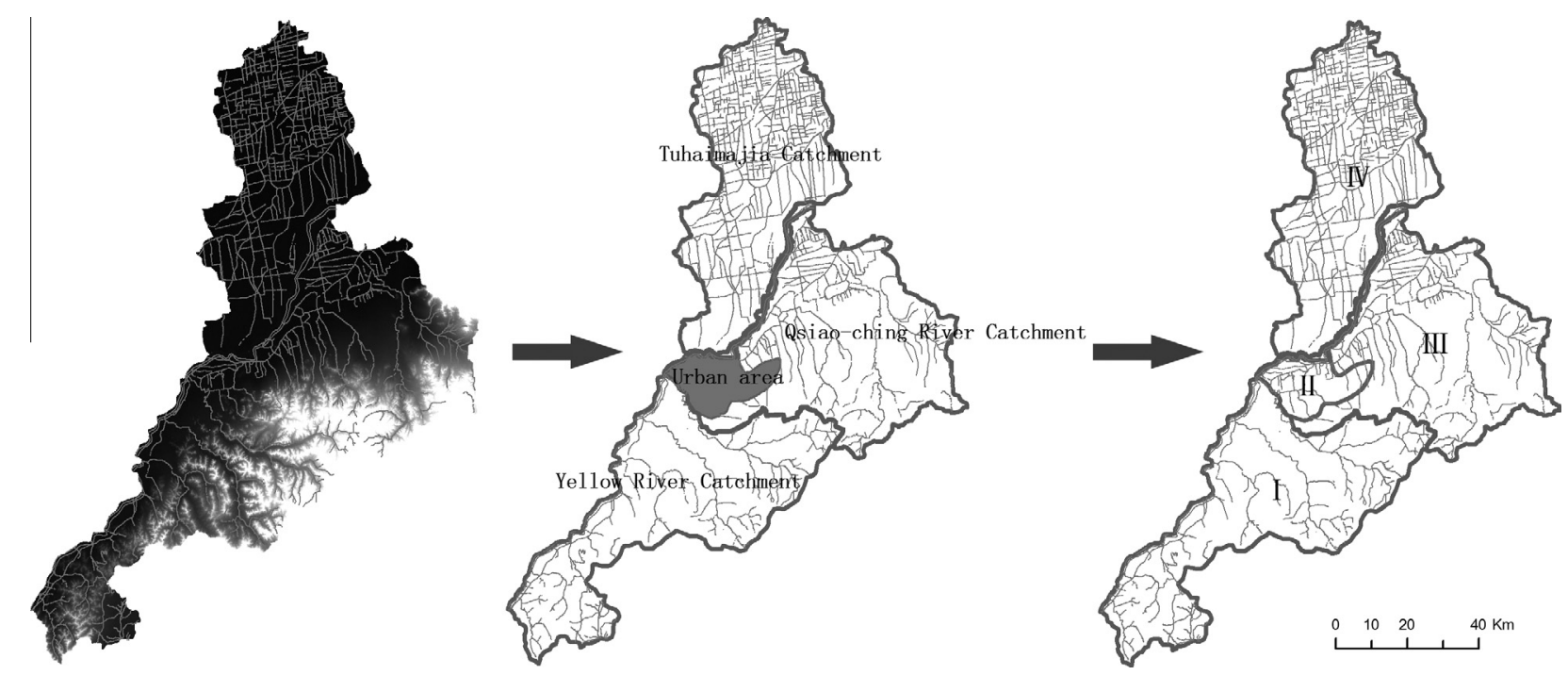

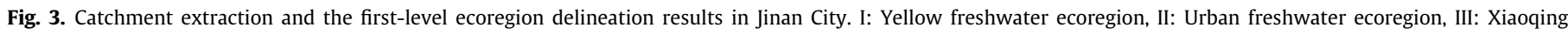
freshwater ecoregion, IV: Tuhaimajia freshwater ecoregion.

Table 2

Comparison of zooplankton community attributes between the urban and natural area.

\begin{tabular}{|c|c|c|c|c|c|c|c|}
\hline \multirow[t]{2}{*}{ Community attributes } & \multicolumn{2}{|l|}{ Mean } & \multicolumn{2}{|c|}{ Std. Deviation } & \multicolumn{2}{|c|}{ Confidence interval } & \multirow[t]{2}{*}{$p$} \\
\hline & Urban & Natural & Urban & Natural & Urban & Natural & \\
\hline Species number & 4.62 & 9.19 & 2.92 & 3.69 & $(2.2,7.1)$ & $(8.0,10.3)$ & 0.02 \\
\hline Density & 26.25 & 183.19 & 18.12 & 202.43 & $(11.1,41.4)$ & $(120.9,245.5)$ & 0.35 \\
\hline Diversity & 1.64 & 2.12 & 0.77 & 0.70 & $(0.9,2.3)$ & $(1.9,2.3)$ & 0.76 \\
\hline Evenness & 0.82 & 0.70 & 0.15 & 0.18 & $(0.7,0.9)$ & $(0.6,0.8)$ & 0.75 \\
\hline
\end{tabular}

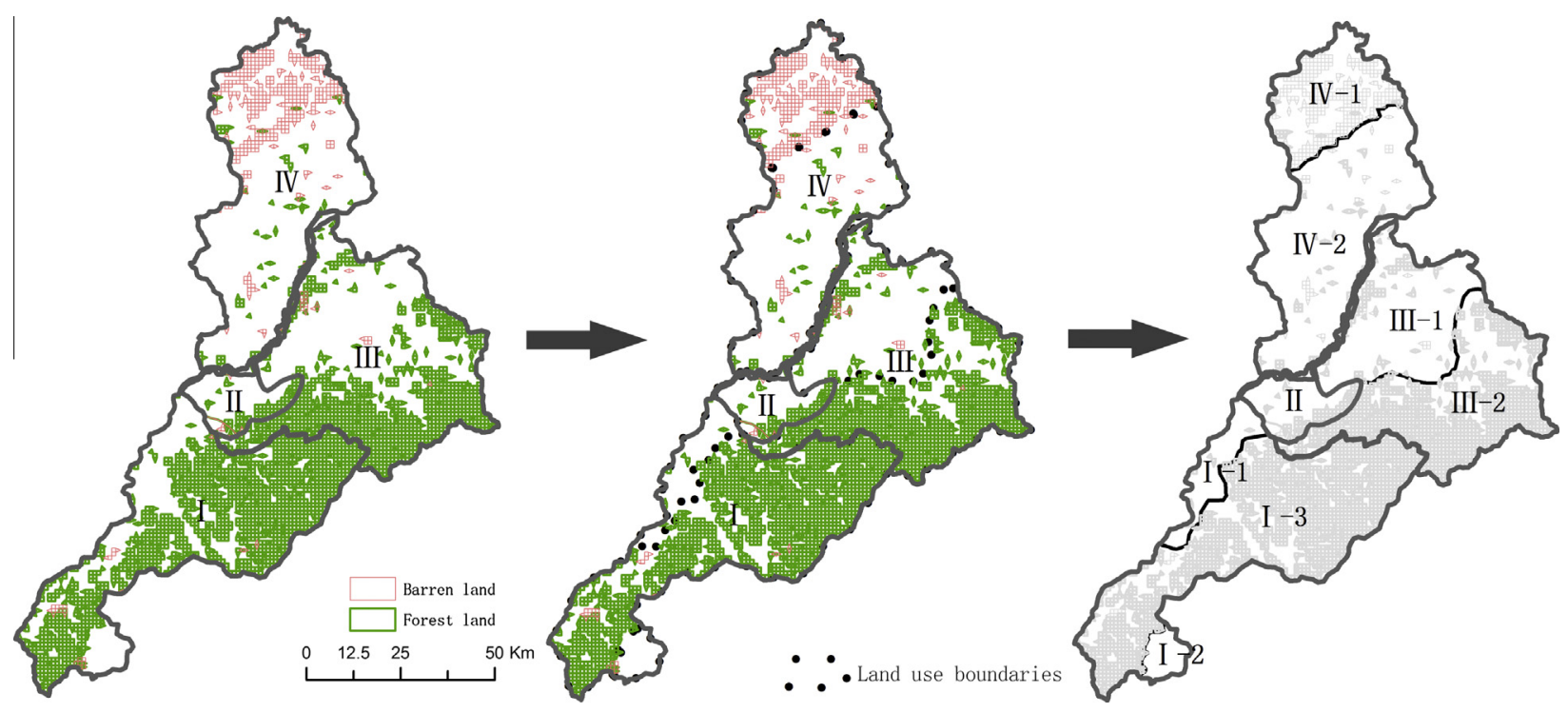

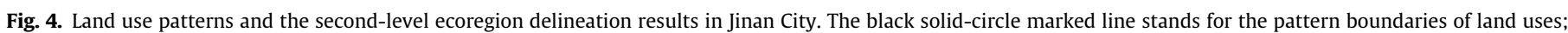

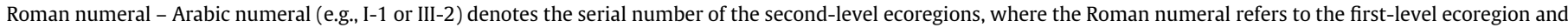
the Arabic numerical indicates the sub-ecoregion within the first level.

within a basin or a political area (Jenerette et al., 2002). It is necessary to employ other freshwater ecological indicators that are not involved in classification to validate the aquatic ecoregion delineation results. Thus, the validation is then made on the basis of the health assessment results of the fish community by comparing the spatial patterns of freshwater ecoregions and the ecological health assessment.
For the fish community, the ecological health assessment method is the Index of Biological Integrity (IBI, see Wu et al., 2014 for details). As shown in Fig. 6, the Yellow freshwater ecoregion (I), except for I-3-3 which was classified as a bad level, had generally healthy results for the fish community. The whole urban area (II) was almost all covered in red, suggesting an extremely severe environment for fish. While for the Xiaoqing freshwater 


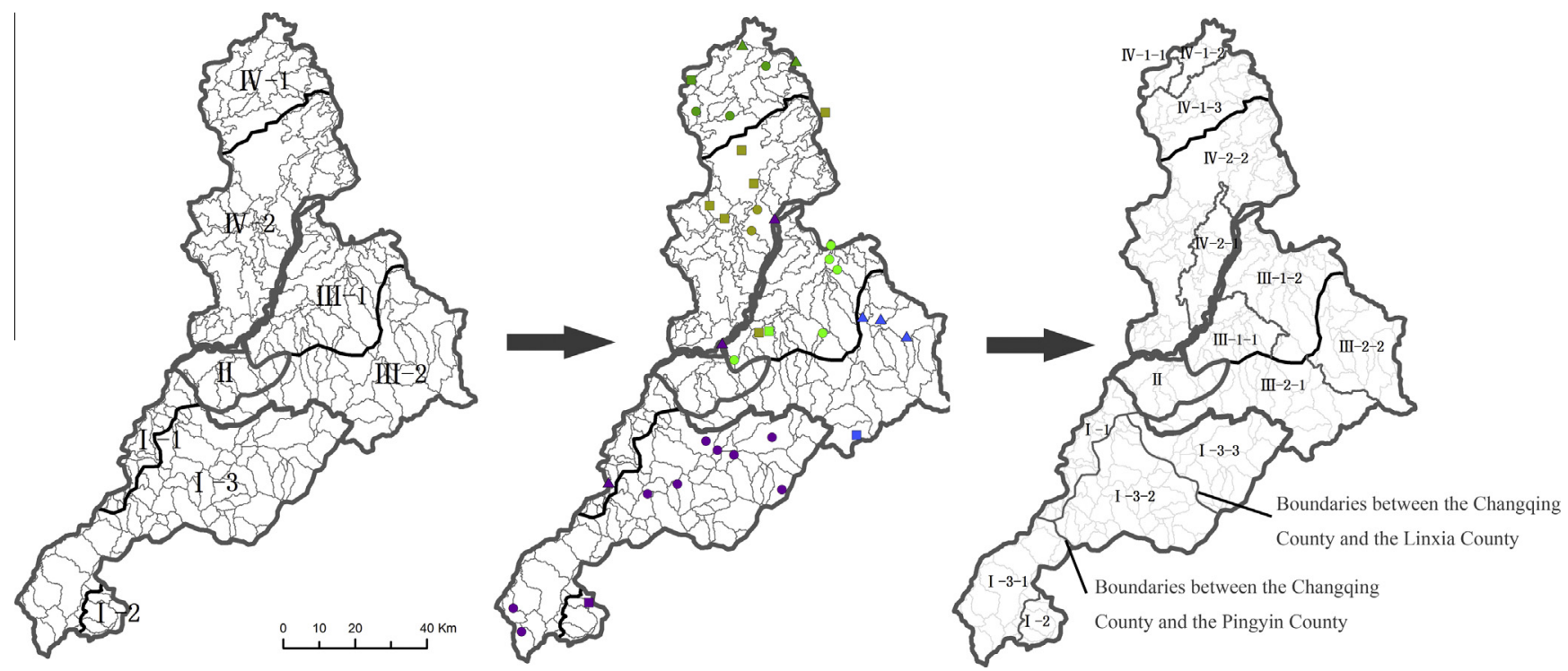

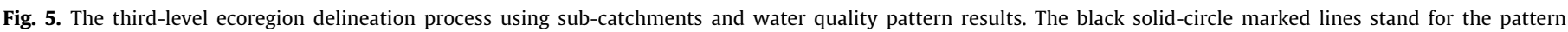

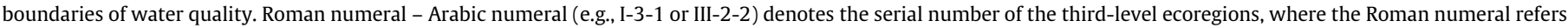

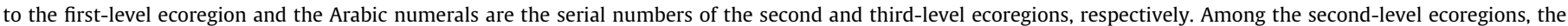

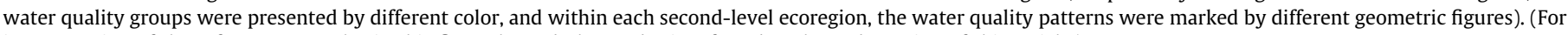
interpretation of the references to color in this figure legend, the reader is referred to the web version of this article.)
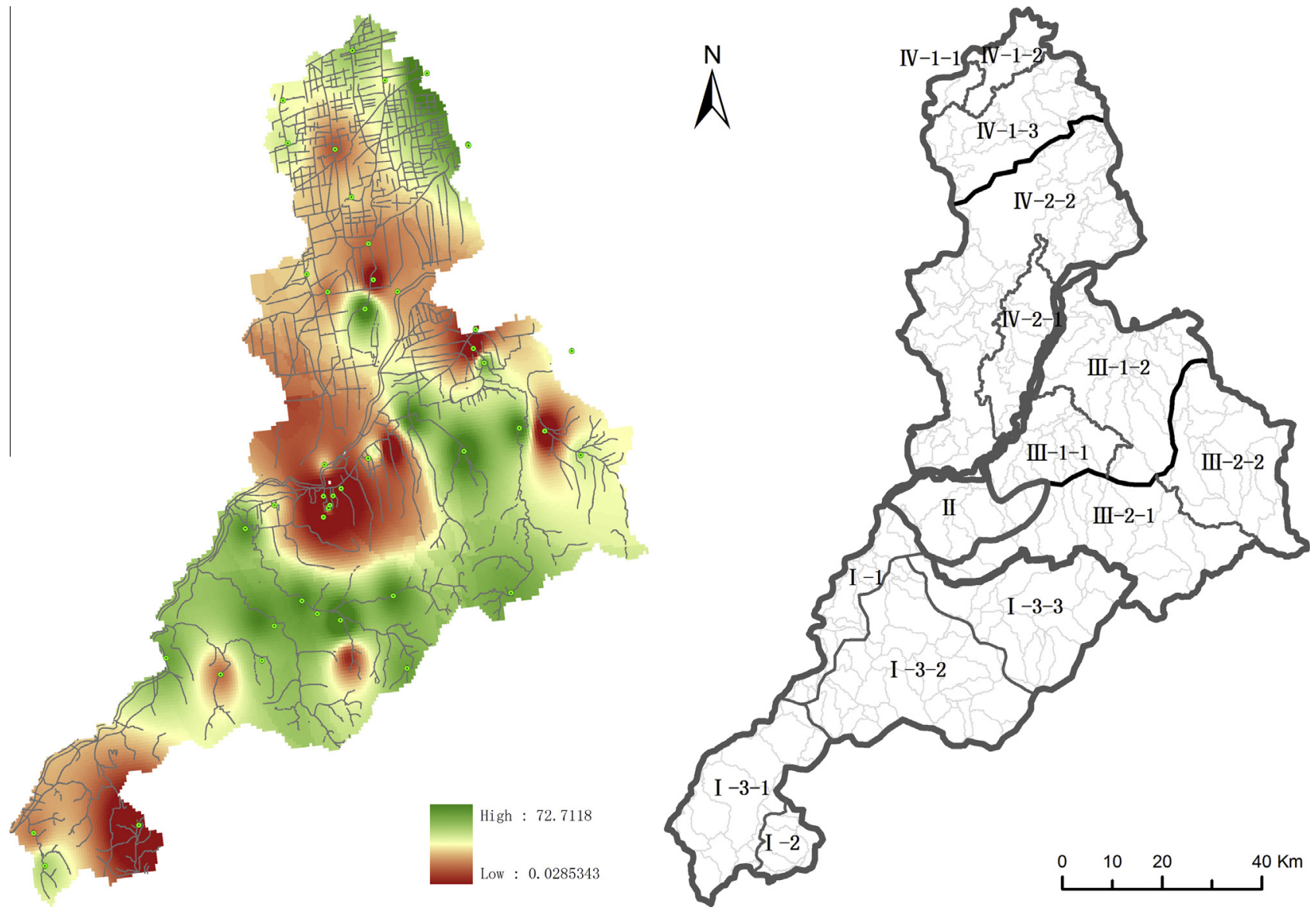

Fig. 6. Comparison of spatial patterns of ecological integrity based on fish community and the aquatic ecoregion map.

ecoregion (III), most areas were in good condition except for two sites located in III-1-2 and III-2-2. In the Tuhaimajia freshwater ecoregion, IV-2-2 showed low biological integrity, although the adjacent IV-2-1 was quite healthy based on the fish community, indicating the reasonable health of the freshwater ecoregion in this area. This is also true for IV-1-1 and IV-1-2. However, the 
Table 3

Consistent results between the freshwater ecoregions and the spatial patterns of biological communities.

\begin{tabular}{|c|c|c|c|c|c|}
\hline \multirow[t]{2}{*}{ Biological communities } & \multicolumn{2}{|c|}{ Consistence } & \multicolumn{2}{|c|}{ Discrepancy } & \multirow[t]{2}{*}{ Agreement percentage (\%) } \\
\hline & Number & Freshwater ecoregions & Number & Freshwater ecoregion & \\
\hline Fish & 11 & $\begin{array}{l}\text { I-1,I-2,I-3-1,I-3-2, } \\
\text { I-3-3,II, III-2-1, } \\
\text { IV-2-1, IV-1-1, IV-1-2 }\end{array}$ & 4 & $\begin{array}{l}\text { III-1-1, III-1-2, III-2-2 } \\
\text { IV-1-3 }\end{array}$ & 73.3 \\
\hline
\end{tabular}

ecological health assessment results in IV-1-3 are divided into two distinct parts, low biological integrity in the western part and high in the eastern part.

The amount and serial number of ecoregions that were in accordance with the spatial patterns of biological health assessment results, and those that were not, were listed in Table 3. As it shows, for the fish community, eleven out of fifteen freshwater ecoregions (73.3\%) were in agreement, suggesting that most of the ecoregions identified in this study showed strongly consistent relationships with aquatic ecological homogeneity in Jinan City.

\section{Discussion}

This study demonstrated that the environmental variables with strong spatial variability could be applied to identify freshwater ecoregions within Jinan City. The ecoregion delineation approach was quantitative and repeatable, and the ecoregion results were consistent with the observed spatial pattern of biological health assessment results based on the fish community.

\subsection{Potential application on another city}

The materials or dataset used in the ecoregion delineation process were available for city governors and stakeholders. River basins were used in the delineation of the first level aquatic ecoregion. In fact, most cities in the world belong to one river basin or cut across several river basins. In the former condition, apparently this type of city would be in a single first-level ecoregion; thus, it makes sense from the second-level ecoregion. While in the latter condition, we believe that the number of first-level ecoregions is expected to be equal to that of river basins because (in terms of hydrology) river waters draining from different drainage basins can never meet each other before they arrive at the outlet of the hierarchical basin (DeBarry, 2004). Thus, different river basins reflect different aquatic environments and ecological attributes, which are similar to the climate zones in terrestrial ecoregion delineations reported by Bailey (2005). Consequently, we recommend river basins as the indicator to delineate the first level freshwater ecoregions. In addition, rivers in urban areas are critical in city development for city governors and stakeholders, which makes urban areas sensitive and significant in ecoregion delineation. The field survey results showed that aquatic ecological community attributes were significantly different in the urban area compared with the natural area (Table 2), so it is recommended that the urban area be viewed as an independent ecoregion.

This is also true for other environmental data that were applied in the ecoregion delineations in this study. For example, DEM was applied to extract river catchments, which was the fundamental indicator for the first level aquatic ecoregions (Fig. 3), and landuse types within the Jinan area were selected to delineate the second level aquatic ecoregions (Fig. 4). For the third level, water quality variables were classified by cluster analysis to subdivide the higher level (Fig. 5). Materials used in urban aquatic ecoregion delineation are also available at the basin scale (Kong et al., 2013), so our method for freshwater ecoregion identification is repeatable for almost any city in the world just by having access to the necessary datasets and dealing with them in the presented way or in any operational manner that is better for the practical conditions.

For the second level freshwater ecoregion, forestland and barren land were used, due to their significant spatial heterogeneity and strong relationship with aquatic ecosystems, especially with water quality (Table 1 ). When ecoregion delineations are developed in other cities, other land use types might be the appropriate indicator. Bailey (2005) found that in some areas problems resulting from the intricate pattern of secondary successional stages make regional boundary placement difficult, so that potential vegetation, rather than actual vegetation, was useful in capturing ecological regions. Actually, these two opinions look at the same question from different perspectives. Our study is based on the current influence of actual land uses on surrounding river ecosystems. The influence may vary with the ecological successions of land use types, but if ecoregion delineation remains flexible enough to accommodate the various environments, the ultimate results would be consistent with those presented by Bailey (2005). In addition, if potential vegetation was applied in delineation in the beginning, the ecoregion results might not match well with actual river ecosystems due to the time lag.

\subsection{Freshwater ecoregion assessment}

An accepted way to test the strength of a classification is to determine whether the ecosystem classes correspond well with sample data on biotic communities within each class (Van Sickle, 1997; Hawkins et al., 2000; Melles et al., 2012; Snelder et al., 2004). Our study made comparisons between the ecoregion classifications and the spatial patterns of ecological health assessment results based on the fish community. Furthermore, the freshwater ecoregions results in Jinan City were also proved to be applicable and valuable by Zhao et al. (2015), where an effective method for assessment of rehabilitation potential was developed, based on the responses of dominant fish species to their changing habitat environment within the first level ecoregions presented in this study.

\subsection{Ecoregion changes in future}

As mentioned, modern classifications need to remain flexible enough to accommodate emerging conceptual models and policy frameworks (Melles et al., 2012). It is widely recognized that all environmental variables, including ones involved in our research, vary over both spatial and temporal scales. Variables that exhibit significant spatial variability in this time might be homogenous next time. Land-form is also changeable because forestland could be exploited into urban land or agricultural fields over a time scale of decades. Consequently, a flexible and up-to-date variable dataset would assure that physically based abiotic ecoregion delineations could be combined with predictive models of climate change to forecast potential shifts in the distribution of various freshwater biotas (Melles et al., 2012).

Although our ecoregion delineation approach is based on statistical methods, such as cluster analysis, which makes our ecoregion results repeatable, there are some unavoidable uncertainties in the 
results. The main source of uncertainty is the water quality variables, which were determined on the basis of the commonly monitored variables at the local hydrographic office, leading to the occurrence of a biased dataset. To reduce this uncertainty, we selected water quality variables according to their importance in ecosystems and environmental quality standards for surface water (GB 3838-2002) issued by the Ministry of Environmental Protection of China. Then, the biased dataset can be more effectively utilized. We also advocate the need for more validation of the freshwater ecoregion results in Jinan City. A major challenge facing freshwater ecoregions is the lack of an explicit link between the objectives of conservation management and the design of a fluvial classification system (Soranno, 2010; Melles et al., 2012). Consequently, the end of freshwater ecoregion identifications is also the beginning of practical applications or tests. Only by application or test can the value or weakness be addressed.

Overall, successful delineation of freshwater ecoregions within a developing city, as well as applicable validation of the delineation, meet the emerging needs for construction of a civilized and ecological city in China, for which Jinan City was selected in the first round. We hope that the case study of Jinan will provide a first attempt to identify freshwater ecoregions in a city, fostering more research on exploring appropriate treatments of modern water resources management.

\section{Conclusions}

Hierarchical aquatic ecoregions, which are useful for ecosystem conservation and water resources management, are delineated in Jinan City in this study. Different methodology from that for delineating terrestrial ecoregions or basin-scale ecoregions are used to address the effects of both natural conditions and human activities on the aquatic ecosystem. That is, the river system combined with administrative boundary is used for ecoregion delineation. To complete this objective, the first level freshwater ecoregions were based on the three river catchments extracted from DEM within the city and the urban area, and four ecoregions were finally identified. Then, land use patterns (forestland and barren land in this study) were applied in the delineation process of the second level freshwater ecoregions, and eight ecoregions were developed in total on the basis of the first level. Furthermore, following the principle that the lowest level groupings were created from bottom to top by clustering fluvial sub-catchments, fifteen third-level ecoregions were identified for Jinan City. At the same time, administrative boundaries were used to rectify the boundaries of each ecoregion in this study to facilitate the administration of each ecoregion.

In addition, ecological health assessments based on the fish community were employed to validate the freshwater ecoregion results presented in this study. Our results demonstrated that $73.3 \%$ of ecoregions were aligned with the distribution patterns of the biological attributes of the fish community, suggesting that the freshwater ecoregions are acceptable and can be applicable and valuable for future water resources management.

\section{Acknowledgement}

This study was supported by the Natural Science Foundation of China (No. 51279005). The authors appreciate the sampling team for their assistance with the field work.

\section{References}

Abell, R., Thieme, M.L., Revenga, C., Bryer, M., Kottelat, M., Bogutskaya, N., Coad, B. Mandrak, N., Balderas, S.C., Bussing, W., Stiassny, M.L.J., Skelton, P., Allen, G.R., Unmack, P., Naseka, A., Rebeccang, N.G., Sindorf, N., Robertson, J., Armijo, E.,
Higgins, J.V., Heibel, T.J., Wikramanayake, E., Olson, D., Lopez, H.L., Reis, R.E., Lundberg, J.G., Sabaj Perez, M.H., Petry, P., 2008. Freshwater ecoregions of the world: a new map of biogeographic units for freshwater biodiversity conservation. Bioscience 58, 403-414.

Allan, D., Erichson, D., Fay, J., 1997. The influence of catchment land use on stream integrity across multiple spatial scales. Freshw. Biol. 37, 149-161. http:// dx.doi.org/10.1046/j.1365-2427.1997.d01-546.x.

Bailey, R.G., 1983. Delineation of ecosystem regions. Environ. Manage. 7, 365-373.

Bailey, R.G., Zoltai, S.C., Wiken, E.B., 1985. Ecological regionalization in Canada and the United States. Geoforum 16, 265-275.

Bailey, R.G., 2005. Identifying ecoregion boundaries. Environ. Manage. 34, S14-S26.

Binckley, C.A., Wipfli, M.S., Medhurst, R.B., Polivka, K., Hessburg, P., Salter, R.B., Kill, J.Y., 2010. Ecoregion and land-use influence invertebrate and detritus transport from headwater streams. Freshw. Biol. 22, 1205-1218.

Davies P.E., Wright J.F., Sutcliffe D.W., et al., 2000. Development of a national river bioassessment system (AUSRIVAS) in Australia. Freshwater Biological Association.

DeBarry, P.A., 2004. Watersheds: Processes, Assessment and Management. John Wiley \& Sons.

DMEER-Digital Map of European Ecological Regions Project, 2000. The Digital Map of European Ecological Regions (DMEER). European Topic Centre on Nature Conservation, <http://www.eea.europa.eu>.

Graef, F., Schmidt, G., SchrÖder, W., Stachow, U., 2005. Determining ecoregions for environmental and GMO monitoring networks. Environ. Monit. Assess. 108, 189-203.

Geleta, S., Sabbagh, G.J., Stone, J.F., Elliott, R.L., Mapp, H.P., Bernardo, D.J., Watkins, K.B., 1994. Importance of soil and cropping systems in the development of regional water quality policies. J. Environ. Qual. 23, 36-42.

Jenerette, G.D., Lee, J., Waller, D.W., 2002. Multivariate analysis of the ecoregion delineation for aquatic systems. Environ. Manage. 29, 67-75.

Hawkins, C.P., Norris, R.H., Gerritsen, J., Hughes, R.M., Jackson, S.K., Johnson, R.K., Stevenson, R.J., 2000. Evaluation of the use of landscape classifications for the prediction of freshwater biota: synthesis and recommendations. J. North Am. Benthol. Soc. 19, 541-556.

Hurley, T., Mazumder, A., 2013. Spatial scale of land-use impacts on riverine drinking source water quality. Water Resour. Res. 49, 1591-1601. http:// dx.doi.org/10.1002/wrcr.20154.

Kennard, M.J., Pusey, BJ., Olden, J.D., Stephen, J.M., Stein, J., Marsh, N., 2010. Classification of natural flow regimes in Australia to support environmental flow management. Freshw. Biol. 55, 171-193.

Liu, X.C., Xu, Z.X., Xu, C., 2010. A framework for aquatic ecoregion zoing. Acta Ecol. Sinica 30, 4804-4814 (in Chinese).

Maxwell, J.R., Edwards, C.J., Jensen, M.E., Paustian, S.J., Parrot, H., Hill, D.M. 1995. A hierarchical framework of aquatic ecological units in North America (Nearctic Zone). General technical report NC-176. US Department of Agriculture, Forest Services, North Central Forest Experiment Station, St. Paul.

Melles, S.J., Jones, N.E., Schmidt, B., 2012. Review of theoretical developments in stream ecology and their influence on stream classification and conservation planning. Freshw. Biol. 57, 415-434. http://dx.doi.org/10.1111/j.1365-2427. 2011.02716.x.

Munne, A., Prat, N., 2004. Defining river types in a Mediterranean area: a methodology for the implementation of the EU framework directive. Environ. Manage 34, 711-729.

Omernik, J.M., 1987. Ecoregions of the conterminous United States. Ann. Assoc. Am. Geogr. 77, 118-125.

Omernik, J.M., Griffith, G.E., 1991. Ecological regions versus hydrologic units: Frameworks for managing water quality. J. Soil Water Conserv. 56, 334-340.

Peterjohn, W.T., Correll, D.L., 1984. Nutrient dynamics in an agricultural watershed: observations on the role of a riparian watershed. Ecology 65, 1466-1475.

Ravichandran, S., Ramanibai, R., Pundarikanthan, N.V., 1996. Ecoregions for describing water quality patterns in Tamiraparani basin, South India. J. Hydrol. 178, 257-276.

Shirmohammadi, A., Yoon, K.S., Magette, W.L., 1997. Water quality in mixed landuse watershed-Pledmont region in Maryland. Trans. Am. Soc. Agric. Eng. 40, 1563-1572.

Sliva, L., Williams, D.D., 2001. Buffer zone versus whole catchment approaches to studying land-use impact on river water quality. Water Res. 35 (14), 3426-3472.

Snelder, T.H., Cattaneo, F., Suren, A.M., Biggs, B.J.E., 2004. Is the river environment classification an improved landscape-scale classification of rivers? J. North Am. Benthol. Soc. 23, 580-598.

Soranno, P.A., 2010. Using landscape limnology to classify freshwater ecosystems for multi-ecosystem management and conservation. Bioscience 60, 440-454.

Summer, R.M., Alonso, C.V., Young, R.A., 1990. Modeling linked watershed and lake processes for water quality management decisions. J. Environ. Qual. 19, 421427.

Van, S.J., 1997. Using mean similarity dendrograms to evaluate classifications. J. Agric., Biol., Environ. Stat. 2, 370-388.

Kong, W.J., Meng, W., Zhang, Y., Christopher, G., Qu, X.D., 2013. A freshwater ecoregion delineation approach based on freshwater macroinvertebrate community features and spatial environmental data in Taizi River Basin, northeastern China. Ecol. Res. 28, 581-592. 
Wen C., 2010. Speciation analysis of heavy metals in the main soil types of Jinan and its surrounding areas - moisture soil, cinnamon soil and brown soil. (Master Degree Dissertation) Shandong University, China

Wu, W., Xu, Z.X., Yin, X.W., Zuo, D.P., 2014. Assessment of ecosystem health based on fish assemblages in the Wei River basin, China. Environ. Monit. Assess. 186, $3701-3716$.
Zhao, C.S., Yang, S.T., Liu, C.M., Dou, T.W., Yang, Z.L., Yang, Z.Y., Liu, X.L., Xiang, H. Nie, S.Y., Zhang, J.L., Mitrovic, S.M., Yu, Q., Lim, R.P., 2015. Linking hydrologic, physical and chemical habitat environments for the potential assessment of fish community rehabilitation in a developing city. J. Hydrol. 523, 384-397. 